\title{
Application of Visual Interactive Concept Map in College English Writing Teaching
}

\author{
https://doi.org/10.3991/ijet.v11i11.6248 \\ Zhuan Ma, Lin Shi \\ Xi'an University of Architecture and Technology, China
}

\begin{abstract}
In order to solve the problem of students' poor thinking in English writing, this paper adopts the concept map method. The visual interactive concept map was tested in 6 levels and 9 types of universities. The test results indicate the method can stimulate students' interest in learning and improve their ability of autonomous learning and increasing the effect of college English writing teaching. The method can also stimulate students' interest in learning and improve their ability of autonomous learning and increasing the effect of college English writing teaching.
\end{abstract}

Index Terms-visual interactive concept map, English writing teaching, interaction and vitality

\section{INTRODUCTION}

In the "College English Curriculum Requirements For Trial Implementation", formulated by Higher Education Department of Ministry of Education, hereinafter referred to as "Requirement", it is clearly pointed out that the objectives of college English is to train the students' comprehensive ability of using English, to make it possible that students can well use English for the oral and written communication in the future work and social activities and meanwhile [1-2], to improve their ability of autonomous learning, enhance their comprehensive cultural quality, to meet the need of social development in our country and international communication.

The college students' comprehensive ability to use English includes Listening, speaking, reading, writing, etc. English writing plays a key role in the college English teaching, with that in CET-4 and CET-6, or mid-term and final exams, the English writing occupies a large score. Therefore, to strengthen the training of college writing ability is an important content which cannot be ignored in the English teaching. Teachers always play a leading role in the traditional English writing teaching, while the students are passively listening, and the teaching contents are basically the sentence structure, grammar or some other templates. This teaching mode seriously affects the quality of college English writing teaching. With the development of information technology, the visual interaction based on the concept map has been continually used in the college English teaching, which can help to train students' ability of autonomous learning in a way, improve their English writing ability, thereby increasing the quality of teaching [3].

The visualization refers to a theory, method and technology which the scientific data are transferred into intuitive graphics or image shown on the screen, then proceeded to interactive processing by using the computer graphics and image processing technology. It was first proposed by Kant who was a German philosopher in the 19th century. In his opinions, the schema refers to a "primary imagination" which is a technique, a skill hidden in the depths of the human mind, and belongs to the transcendental category. While in the later studies by Piaget, Bartlett and Rumelhart, the schema is a kind of cognitive structure existing in subject, and it is dynamic and variable. The concept map refers to a kind of graphic method with that nodes represent the concept and links represent the relations between concepts. The theoretical basis of it is the Ausube Fs learning theories which was first proposed by Prof. Novak, Cornell University, in the 1960s. This theory was proposed when he was in the research on the case of children's subject knowledge comprehension and was applied to the teaching, and then gradually became an important way for teaching. The construction of knowledge starts from observation and cognition of things through the existing concept. The study is regarded to that the students establish a concept network and then constantly supplement new contents to the network. In order to make learning meaningful, the individual learners should make a link between the new knowledge and the learned concept [4-7].

In order to solve the problem of students' poor thinking in English writing, this paper adopts the concept map method. This paper mainly studies the application of the concept map method in English writing teaching from five parts. The first section is the preface which introduces the study purpose, background, content and methods of this paper. The second section is the overview part. It summarizes the related researches of the concept map method in English writing teaching, both at home and abroad. The third section is an important part of this article which dissects the necessity and viability to establish a concept map model in the English writing teaching. It reveals the interdependence and promoting relationships between the concept map methods in the English writing teaching. It introduces the basic algorithm in the English writing teaching. The fourth section makes a detailed mode of the concept map method in the English writing teaching. The experiment is done in this part. The fifth section discusses the comparison result and data obtained in the fourth part.

\section{OVERVIEW}

The visualization refers to a theory, method and technology which the scientific data are transferred into intuitive graphics or image shown on the screen, then proceeded to interactive processing by using the computer graphics and image processing technology. It was first proposed by Kant who was a German philosopher in the 19 th century. In his opinions, the schema refers to a "primary imagination" which is a technique, a skill hidden in the depths of the human mind, and belongs to the transcendental category. While in the later studies by Piaget, Bartlett and Rumelhart, the schema is a kind of cognitive structure existing in subject, and it is dynamic and variable. 
Concept maps originated with the research of Cognitive Psychology. It is an important tool to organize, represent, and share knowledge. Building a concept map involves creating text-based nodes and specifying their relationships with line-based links. Node means a concept and link means the relationship between certain nodes. Current concept map tolls usually impose specific task structures for node and link construction, which means must specify the kind of concept maps before the end the text. By this way, it may increase users' cognitive burden to generate and interact with concept maps. And also this manner will limit users' thinking and the flexible of the concept map tool. Similarly, it is difficult to modify the built concept map. Furthermore, while some pen-based devices offer users more freedom in drawing concept maps with a pen or stylus more naturally, the support for hand-drawn concept map creation and manipulation is still limited. Lastly, currently concept maps tool have different emphasis, specifically for education, there is no enough concept map. To solve the problem mentioned above, Lalsangpuii's article [8] designs and implements a concept tool which is auto generated based on pen gesture. This can be used in the English writing teaching.

The conceptual scheme refers to a positive response of the students based on their previous experience and a process of that the new information is absorbed through the pre-existing information in brain. The formation of students' conceptual scheme is on the basic of the existing schema stored in the brain. An interaction based on the concept map refers to that a process of the interactive construction of new scheme is conducted and during this process, a constantly modify for the original schema is involved. This interactive schema is influenced by the previous schema. The visualization of schema interaction mainly introduced as an interactive model that through the use of modern information technology and schema theory, the individual recessive schema is expressed by a concept map, striving to form visualization between teachers and students and between students and students.

Good representations of knowledge always facilitate the problem solving. The concept maps are means of knowledge representation. We extend this tool to active semantic networks by introducing the duplicator agents, erase agents and adding principle port in relations. The definitions of in interactive concept map and its language are used for English writing teaching. The good representation capabilities are illustrated by examples as the results.

The continuity of a sentence is closely related to the quality of college English writing, if there is a incoherency of the sentence expressing in an article, the quality of English writing will be influenced. As we all know, an article consisted of a title, topic sentences and details. The continuity of the writing language is achieved by that the detailed content should support the topic sentence and the title; if this cannot be achieved, the logic of the whole article will be disordered, thereby influencing the quality of the article. Currently, the students do not pay much attention to the English writing training. They often memorize some fixed sentence in order to use them for the examination and ignore the use of transitional word or conjunction showing causal relationship as well as progressive relationship. While these words are play an important role in the English writing for that if they are omitted, the logic thinking of whole paper will be unclear, and the will be a lack of relationship between detailed content in chapter, thereby affecting the quality of the entire article. Visual concept map has a strong advantage in dealing with logical consistency in English writing teaching. Figure 1 shows the comparison of traditional English writing teaching systems. The promotion of college English writing ability is not achieved in a day. It needs a constant accumulation. The visual interaction based on the concept map is carried out based on the existing knowledge, which refers to that the process of its formation is achieved by a process of interactive construction of a new map on the basis of the existing map stored in brain, in which the constant modification for original schema is involved. In college English writing teaching, the vocabulary learning and the grammar or sentence learning are the process of constructing new culture, and the visual interaction of concept map-based visualization is achieved based on the stimulation of the students' prior knowledge map, to further construct the new concept map by the well-designed video, audio or courseware, etc. The concept map-based visualization can help students constantly update and extend new knowledge, and with this teaching mode, the learning outcome of students and the quality of English writing teaching will increased. A case of visual interactive concept map based teaching system is shown in the figure 2 .

Concept map is originally used in science major to help students organize increasing knowledge. Because of its successful application in science major, it is also widely used in other majors. Concept map helps students construct knowledge actively, and make what is abstract concrete. This function can help students organize the flow of information, which is quite abstract, and make the relationship between information become clear, thus improving the coherence of essay.

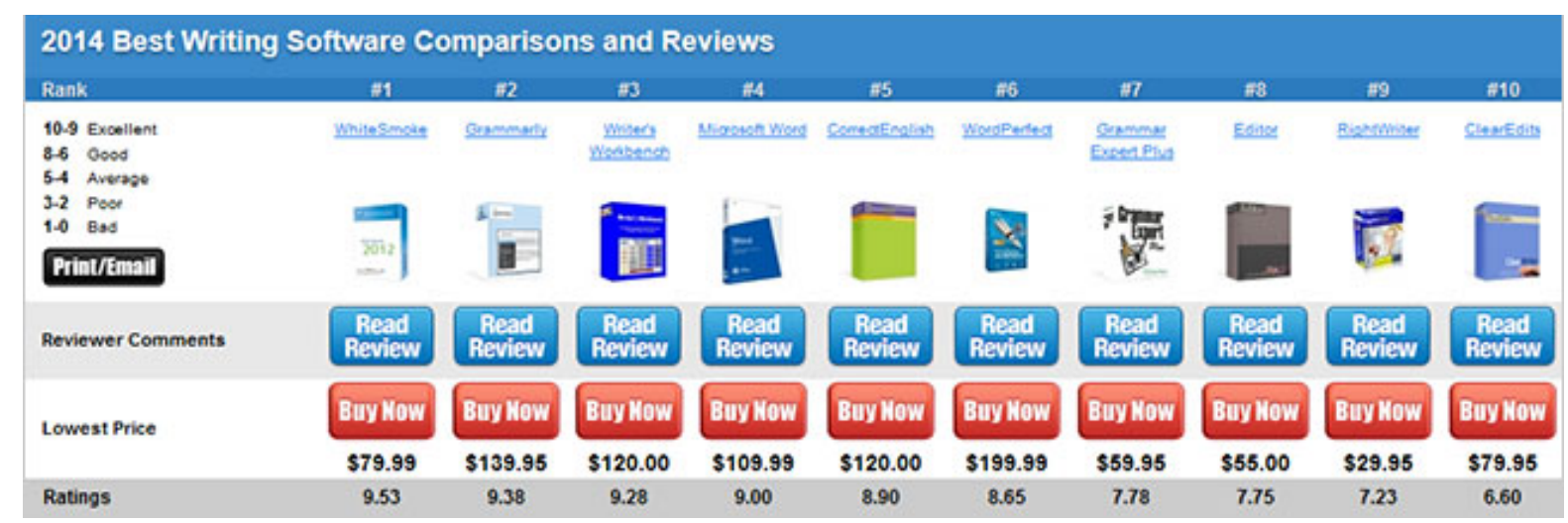

Figure 1. The comparison of traditional English writing teaching systems 


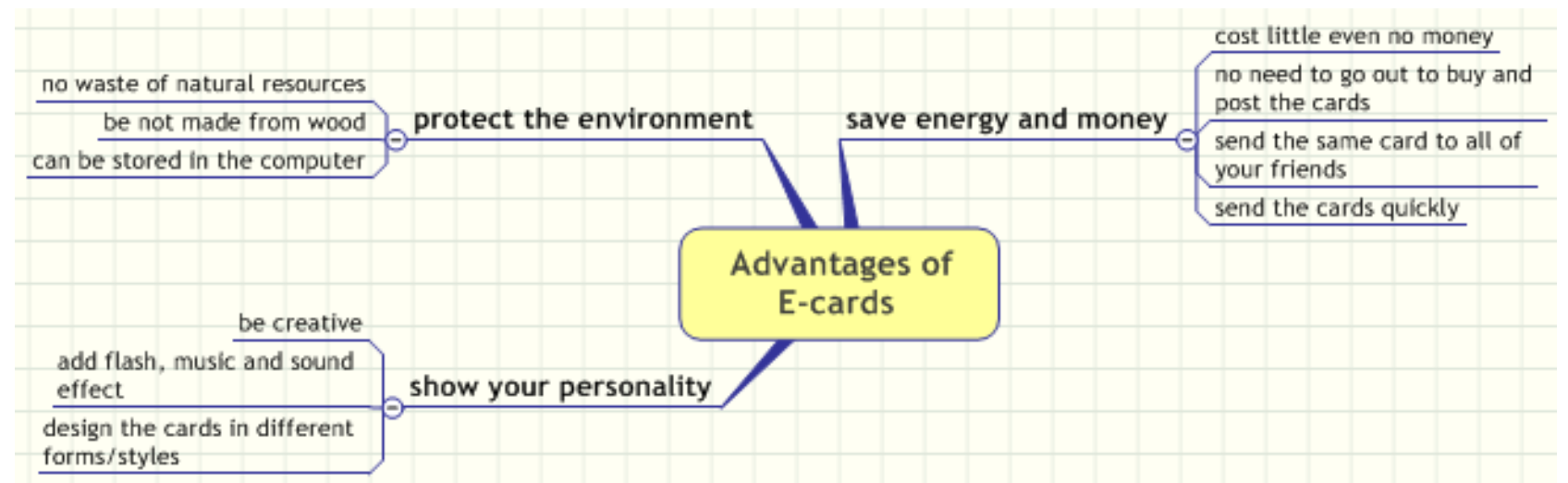

Figure 2. A case of visual interactive concept map based teaching system

\section{METHOD AND ALGORITHM}

From the foregoing discussion process, you can learn the process of clustering analysis is multivariate statistical analysis, which defines the main effective thing is the accordance with property classification process, and then there will be the relationship between the properties of the analysis, such is the basic process of cluster analysis. However, cluster analysis is based on the effective classification of relationships between the variables, usually regarded a sample or a variable as point in the multidimensional space, and then to calculate the distance between two points. Yet another method is to descript the degree of similarity between the elements of the samples selected according to its closeness degrees. In this paper, according to the former corresponding cluster analysis and data for the specific assessment of college students' English assessment, in order to get the cluster diagram pedigree, this can be established by the spectral characteristics of the student's ability and knowledge of the structure with the same effective classification [9-10].

In contrast to the rapid development of software industry, especially open source projects, we lack effective and efficient plagiarism detection tools to protect them from piracy. It is an important tool to organize, represent, and share knowledge. Building a concept map involves creating text-based nodes and specifying their relationships with line-based links. Node means a concept and link means the relationship between certain nodes. Current concept map tolls usually impose specific task structures for node and link construction, which means must specify the kind of concept maps before the end the text. By this way, it may increase users' cognitive burden to generate and interact with concept maps. And also this manner will limit users' thinking and the flexible of the concept map tool. Similarly, it is difficult to modify the built concept map. A less self-disciplined developer, who committed software plagiarism, may elude punishment by seriously disguising the original open source projects. Existing Program Dependence Graph (PDG) based approaches can identify a few kinds of intentional disguises. However, they are rather slow and can be defeated by PDG affecting disguises. We develop a Type Dependence Graph (PDG) based plagiarism detection tool called TPLAG. TPLAG reduces the time complexity of graph based plagiarism detection from exponential to polynomial, and can see through several disguises that confuse existing tools [11].

Supposing the output of a random process is $y$. When $y$ is generated, this random process may be influenced by some relevant context information, $y \in Y, x \in X$. X and $\mathrm{Y}$ are finite sets. Our task is to construct a statistical model to express this random process accurately. When context $x$ is given, the condition probability $p(y / x)$ of output y should be estimated. A collection of all condition probability distribution is $\mathrm{P}$. Some training samples are selected. That is $\left(x_{1}, y_{1}\right),\left(x_{2}, y_{2}\right), \ldots \ldots,\left(x_{N}, y_{N}\right)$. The empirical probability distribution is:

$$
\bar{p}(x, y)=\frac{1}{N} \cdot \text { the number of occurrences of }(x, y)
$$

Firstly, the characteristic function is introduced. For example, the probability of the word make being translated into meaning of write is small. If the word make is followed with treaty, the probability of the word make being translated into meaning of write is big. In order to express this event, following characteristic function can be used. $f(x, y)=\left\{\begin{array}{lc}1, & \text { if } y=\text { "write" and "tready" follows } \\ 0, & \text { otherwise }\end{array}\right.$

It is a binary function, event is the $Y \times X$ space is mapped into $(0,1)$ space. For any characteristic function $f_{i}$, experience expectation on training sample is

$$
E_{\bar{p}} f_{i}=\sum_{x, y} \bar{p}(x, y) f_{i}(x, y)
$$

The expectation of characteristic function $f_{i}$ is

$$
E_{p} f_{i}=\sum_{x, y} \bar{p}(x) p(y / x) f_{i}(x, y)
$$

For the first step, the vocabulary is one of the most important things in the beginning of English writing. Figure 3 and 4 shows the vocabulary teaching based on visual interactive concept map.

The above discussion shown that it cannot be ignored to adopt reasonable assessment of college English teaching, no matter it is in normal teaching activities or grouping teaching. Currently, the students do not pay much attention to the English writing training. They often memorize some fixed sentence in order to use them for the examination and ignore the use of transitional word or conjunction showing causal relationship as well as progressive relationship. However, grouping according to the ability of the students, the appraisal process has not been paid sufficient attention, conversely, there are too many attentions 
and efforts were made to the exams, thus there's no quantified assessment in terms of the ability to process more scientifically. This article introduces and explains cluster analyses, which will make this quantitative assessment method functioning in the research of College English. Figure 5 shows the result of association method based on visual concept map when the writing title is "Education".

\section{EXPERIMENT RESULT}

In 2015, HED of MOE declared that the new CECR was formally issued and could be adopted by all the universities in China. The CECR lists three specifies requirements for each of English abilities for which students should reach. The three requirements are basic requirements, intermediate requirements and the advanced requirements. Each level requires students to reach certain standards in listening, speaking, reading, writing and translating after first two years of compulsory English study in the university.

In the experiment part, there are 6 levels in the 9 types of universities, the best scores are mainly witnessed the best universities of the first batch undergraduate universities. Then the best of the second batch universities and the middle ones of the second batch universities followed as the second level. And the middle ones of the second batch universities and the colleges are belongs to the third level. The worst ones of the first batch universities are the forth level. The middle ones of the colleges and the worst of the second batch universities are the level five, and the rest are the level six. There are 9 levels of the 206 universities, and the result of the sub-items was as followed Table 1.

\section{DISCUSSION}

Visual interaction based on conceptual map is a technology of fully using the modern information technology to operate schema theory, and then to express the individual recessive map via conceptual graphs, which strives to the form a visual interaction mode between teachers and students and among students. The practical application of the visual interaction based on the concept map has made a very good effect in the teaching of English writing, which can stimulate students9 interest in learning, and improve their self-learning ability. As for the main problems currently exist in the teaching of English writing, the author proposed some effective strategies in the perspective of the visual interaction based on the concept map.

Group A and group B differed in that they received different periods of class which used concept map to teach argumentative writing. A pre-test and post-test were ad-

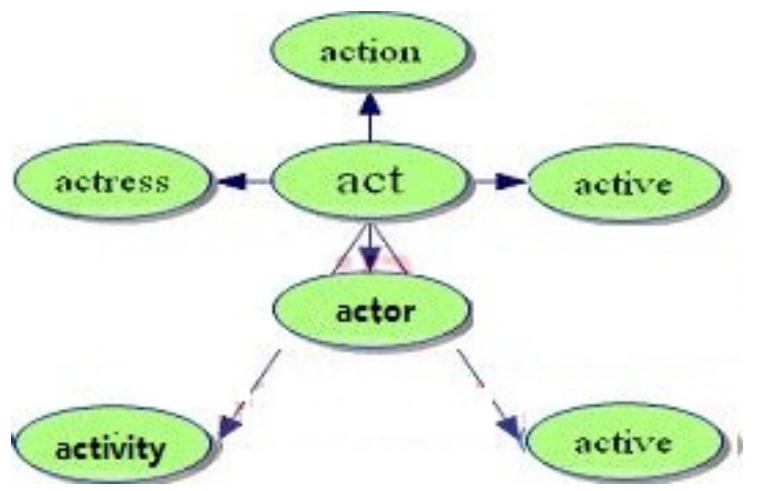

Figure 3. Association method based on visual concept map

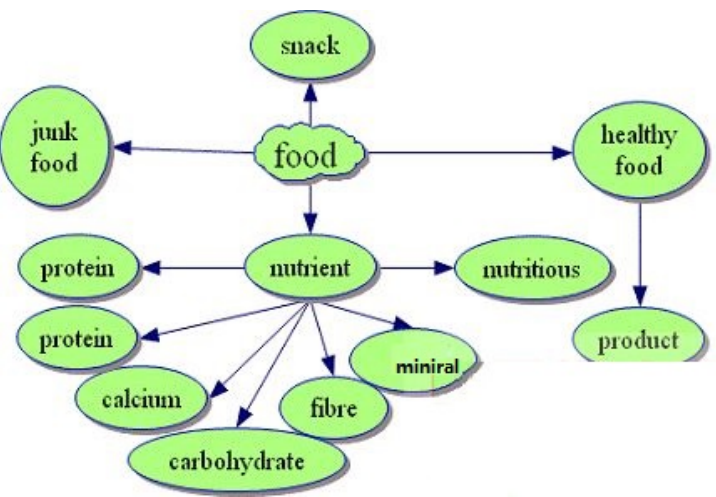

Figure 4. Extend result of association method based on visual concept map

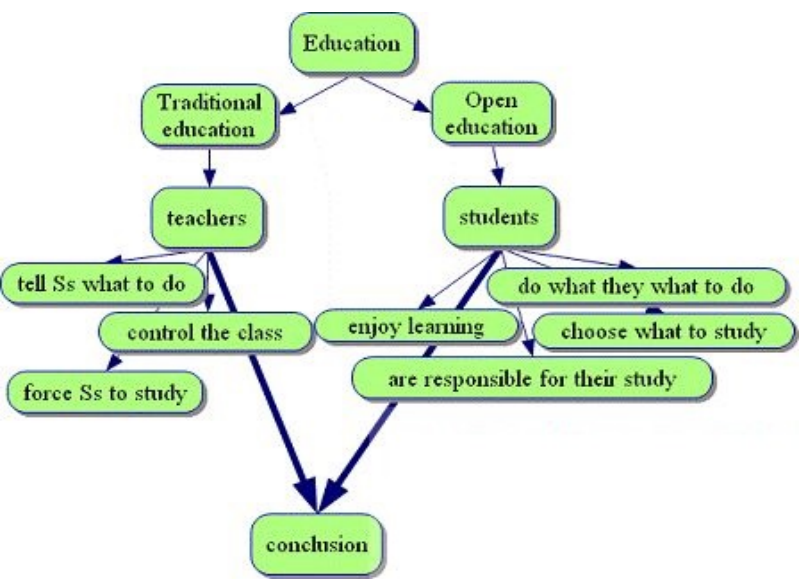

Figure 5. The result of association method based on visual concept map when the writing title is "Education"

TABLE I.

THE 9 LEVELS OF SUB-ITEMS

\begin{tabular}{|c|c|c|c|c|c|c|c|c|c|}
\hline \multicolumn{1}{|c|}{ Type of the university } & \multicolumn{9}{|c|}{ No. of the sub-items } \\
\hline \hline category & 1 & 2 & 3 & 4 & 5 & 6 & 7 & 8 & Total \\
\hline 1st level & 0.94 & 0.91 & 0.78 & 0.98 & 0.91 & 0.88 & 0.88 & 0.63 & 0.84 \\
\hline 2nd level & 0.84 & 0.78 & 0.66 & 0.90 & 0.74 & 0.85 & 0.75 & 0.62 & 0.74 \\
\hline 3rd level & 0.86 & 0.81 & 0.68 & 0.92 & 0.77 & 0.84 & 0.75 & 0.50 & 0.73 \\
\hline 4th level & 0.81 & 0.75 & 0.61 & 0.89 & 0.70 & 0.82 & 0.70 & 0.41 & 0.67 \\
\hline 5th level & 0.78 & 0.72 & 0.60 & 0.83 & 0.67 & 0.73 & 0.65 & 0.53 & 0.66 \\
\hline 6th level & 0.76 & 0.68 & 0.57 & 0.82 & 0.62 & 0.76 & 0.60 & 0.38 & 0.62 \\
\hline 7th level & 0.71 & 0.64 & 0.53 & 0.75 & 0.58 & 0.71 & 0.57 & 0.47 & 0.59 \\
\hline 8th level & 0.65 & 0.58 & 0.49 & 0.68 & 0.50 & 0.62 & 0.47 & 0.37 & 0.52 \\
\hline 9th level & 0.57 & 0.50 & 0.43 & 0.57 & 0.39 & 0.50 & 0.36 & 0.28 & 0.44 \\
\hline
\end{tabular}


ministered to all students with the statistical methods of one-way ANOVA to test if there were any changes after the application of concept map in their performance in coherence. Interview and questionnaire would also be implemented to investigate the changes in students' attitude towards argumentative writing. Results revealed that the test groups A and B outperformed those students in the control group concerning the coherence in their writing tasks. Additionally, group A performed better than group $B$ in the same area since group A received twice the periods of class that of group B. Paired-sample t-test is also employed to test within each group to determine if there is any improvement after the experiment. The results show that students in group A and group B do a better job after the experiment while there is no evident change in students from group $\mathrm{C}$. In terms of the attitudes towards the argumentative writing, it is shown that after the class, students in test groups revealed greater enthusiasm towards argumentative writing.

The design of concept map plays an important role in the visible teaching of college and has an effect on integrating words and pictures for the visualization teaching design. English and the design of word cloud integration will directly impact on the effect of visual teaching. Visual interaction requires students to be able to link the new knowledge with prior concepts. And teachers require welling designing the concept map of visual interaction in the teaching of English writing, so as to display the teaching contents in the form of video, audio or drawings form. Conceptual map has intuitive and memorable characteristics. Based on the cognitive characteristics of students, the visual cloud chart can show the teaching content to students by a variety of maps. But concept map is not designed in a casual way. It should be based on students' actual needs and existing knowledge content, and the map should be targeted to the related contents. Conceptual map design must focus on attracting students. For example, as for the design of the vocabulary, synonyms, synonyms, similar words with the same suffix can be put together to make students build up new conceptual map. This design will help to improve students' learning.

\section{CONCLUSION}

In order to solve the problem of low interaction and low energy efficiency in English writing teaching process, the visual interactive concept map is used in this paper. The practical application of a visual interaction based on the concept map used in college English writing teaching has achieved a good result. It can stimulate students' interest in learning and improve their ability of autonomous learning and increasing the effect of college English writing teaching. It can stimulate students' interest in learning and improve their ability of autonomous learning and increasing the effect of college English writing teaching. Simulation results show that the visual interactive concept map can thus improve interaction and vitality in English writing teaching process.

The modem education concept requires that the initiative and enthusiasm of students should be mobilized, the logic thinking and intelligence of students should be developed and the consciousness and the ability of students' autonomous learning should be cultivated. The construction of concept map-based visualization needs the students 9 active participation based on their existing knowledge. For this, it requires that the old and traditional teaching mode of taking the teacher as the center should be transferred to a mode of that the students are the center in the teaching. How to help the students to stimulate the exist- ing schemata has become a question which teachers should pay much attention to. The map visualization is simply achieved by related videos or PPT designed by teachers, it requires a process of stimulating the existing schema information in brain. Therefore, the college English teaching needs a well-designed teaching situation and an active classroom atmosphere to attract the students to actively participate in the classroom teaching. Let the students to discuss writing by way of practice in the classroom, and students share their opinions through the discussion and communication to expand their horizons, thereby enriching their writing material and no longer constrained to a single inherent thinking.

From the experiment result above, the author found that the problems in the use of words and grammar are the key in factor of affecting the quality of students' English writing. Conceptual map has intuitive and memorable characteristics. Based on the cognitive characteristics of students, the visual cloud chart can show the teaching content to students by a variety of maps. But concept map is not designed in a casual way. For example, teachers often teach the imitative writing of first paragraph, the use of linking sentence in the second paragraph analysis and for the last paragraph, there is always a imitative writing, which ignore the logical relations of discourse and the context, cohesion and transition of text, text structure, writing style as well as the internal relations of related knowledge, and avoid the overall grasp of article. It should be based on students' actual needs and existing knowledge content, and the map should be targeted to the related contents.

\section{REFERENCES}

[1] Y. Z. Chang, "English Teaching in China," Applied Mechanics \& Materials, vol.19, no.1, pp.12-34, 2014.

[2] H. Jing, "The Study on the Impact of Data Storage from Accounting Information Processing Procedure," International Journal of Database Theory and Application, vol. 8, no.3, pp. 323-332, June 2015. https://doi.org/10.14257/ijdta.2015.8.3.28

[3] M. Gamo, "Model of English Teaching for Future Employees in China's Petroleum Production Industry," Studies in Literature \& Language, vol. 8, no.1, pp.20-23, 2014.

[4] R. Misson, "Understanding About Water in Liquid Modernity", Critical Imperatives for English Teaching,vol.49, no.1, pp.27-35, 2014.

[5] J.S. Curwood, A. O'Grady, "Answering the Call: Ref lections on Professional Learning and English Teaching," English in Australia (0155-2147), 2015.

[6] Y. Yang, and K. Yu , "Construction of Distance Education Classroom in Architecture Specialty Based on Internet of Things Technology," International Journal of Emerging Technologies in Learning, vol. 11, no.5, pp. 56-61, May 2016. https://doi.org/10.3991/ijet.v11i05.5695

[7] F. Zhao, G. Li, R. Zhang, et al., "Swarm-based intelligent optimization approach for layout problem," Multimedia Tools and Applications, pp. 1-17, 2015.

[8] Lalsangpuii, "The Problems of English Teaching and Learning in Mizoram," Language in India, 2015.

[9] F. Wang, "A visual teaching design for senior English with word cloud integration," Shanghai Research On Education, no.6, 2013.

[10] W.Z. Zhang, H. R. Tang, "The five principles of visual teaching content design," E-education Research ,no.10,2010.

[11] X. Zhang, "Study on the application of visual interaction based on concept map in English reading teaching," China Educational Technology,no.03, 2013.

\section{AUTHORS}

Zhuan Ma and Lin Shi are with Xi'an University of Architecture and Technology, China (e-mail: mazhuan@chinauniedu.com).

Submitted 09 September 2016. Published asresubmitted by the authors 03 November 2016. 